\title{
Dangerous geodynamic processes of the Eastern Orenburg
}

\author{
Maksim Nesterenko ${ }^{1, *}$, Aleksey Tsviak $^{1}$, Olga Kapustina $^{1}$, Aleksey Nesterenko ${ }^{1}$, and Sergey \\ Nikiforov $^{2}$ \\ ${ }^{1}$ Orenburg Federal Research Center, UB RAS, Orenburg, Russia \\ ${ }^{2}$ NUST MISIS College of Mining, Moscow, Russia
}

\begin{abstract}
The article raises a problem of dangerous geodynamic processes taking place in the eastern part of Orenburg region. The analysis of subsoil geodynamic state of Orenburg region is completed. Effective monitoring of geodynamic processes in the eastern part of Orenburg region using a seismological network is proposed and justified. Seismic events with a magnitude of $\mathrm{M}_{\mathrm{L}}>2.0$ are confidently recorded on this territory as well as subsidence of land surface reaching $50 \mathrm{~cm}$ per year. According to long-term monitoring of seismic events in the eastern part of the Orenburg region, a repetition schedule of seismic events was constructed. It allowed us to make a conclusion of the reason for increased geodynamic activity in this region is high technogenic load on geological environment. To study abnormally high seismic activity in the East Orenburg region, it is necessary to create a seismological network of 3-4 seismic stations in the territory of seismic activity in the Gaysky and Novooorsky districts near the cities of Orsk and Gai, Iriklinskaya State District Power Station and Iriklinskoye Reservoir. This will help to identify seismic activity causes and sources, level of danger, help to develop measures for reducing seismicity and increase the security of specific objects of society, industry and energy.
\end{abstract}

\section{Introduction}

Mining industry development in Russia and the Orenburg region leads to increase in load on geological environment, which leads to geodynamic processes appearance, phenomena in the bowels and on surface and leads to tragic consequences. This problem is especially acute at mining sites. During extraction of solid minerals, the number of dynamic manifestations of rock pressure at mining facilities increases. In majority of regions, there has been a steady increase in the share of large events such as man-made earthquakes, which are accompanied by great damage to mine workings and on surface with negative, including tragic, consequences. Such events are already taking place at mining enterprises in Russia and in the world. For example, a series of earthquakes and catastrophic failures in the Perm Territory in the city of Solikamsk and Berezniki at mine workings of the Verkhnekamsk deposit, in the Sverdlovsk region in areas of the Kizel coal basin development, at the copper ore quarry in Uchaly (Bashkortostan). A strong earthquake with $\mathrm{M}_{\mathrm{L}}=6.1$ with severe consequences was recorded in the Kuzbass region near the Bagatsky section.

Most mining enterprises (including the Perm Territory, Kuzbass, etc.) are monitoring seismic and geodynamic activity of geological environment of a developed mineral deposits. Seismic monitoring involves creation of a network with stationary and mobile seismic

\footnotetext{
* Corresponding author: geoecol-onc@ mail.ru
} 
stations and its compaction in identified geodynamically and seismically hazardous areas. Geodynamic monitoring involves highly accurate periodic observations of land surface movement at workings, sides and ledges of quarries and in their vicinity. Geodynamic monitoring only allows us to record facts of dangerous processes on surface, whereas seismological monitoring allows us to continuously identify zones and sections of the bowels which accumulation of tension. Based on integrated seismic activity monitoring of a subsoil and land surface movements, it is possible to predict dangerous geodynamic phenomena for risk reducing of technological and natural-technological disasters

\section{Methods}

Orenburg Federal Research Center of the Ural Branch of Russian Academy of Sciences together with Orenburg Region Russian Ministry of Emergencies has been monitoring seismic and geodynamic activity in the western part of Orenburg region since 2005. Seismic events with magnitude $\mathrm{M}_{\mathrm{L}}>2.0$ are confidently recorded in this territory. To clarify parameters of recorded seismic events, data from seismic stations in Bashkortostan and in Perm Territory are used. Monitoring of seismic activity in the western Orenburg region allowed us to obtain a large amount of factual material about its geodynamics. Due to data analysis we concluded that there is a significant technogenic effect on seismic activity of a subsoil of the region. In areas of exploited hydrocarbon fields, density of released seismic energy is three or more times higher than in areas not subject to technogenic impact [1-5]. Fig. 1 shows the registration capabilities of an existing network of seismic stations.
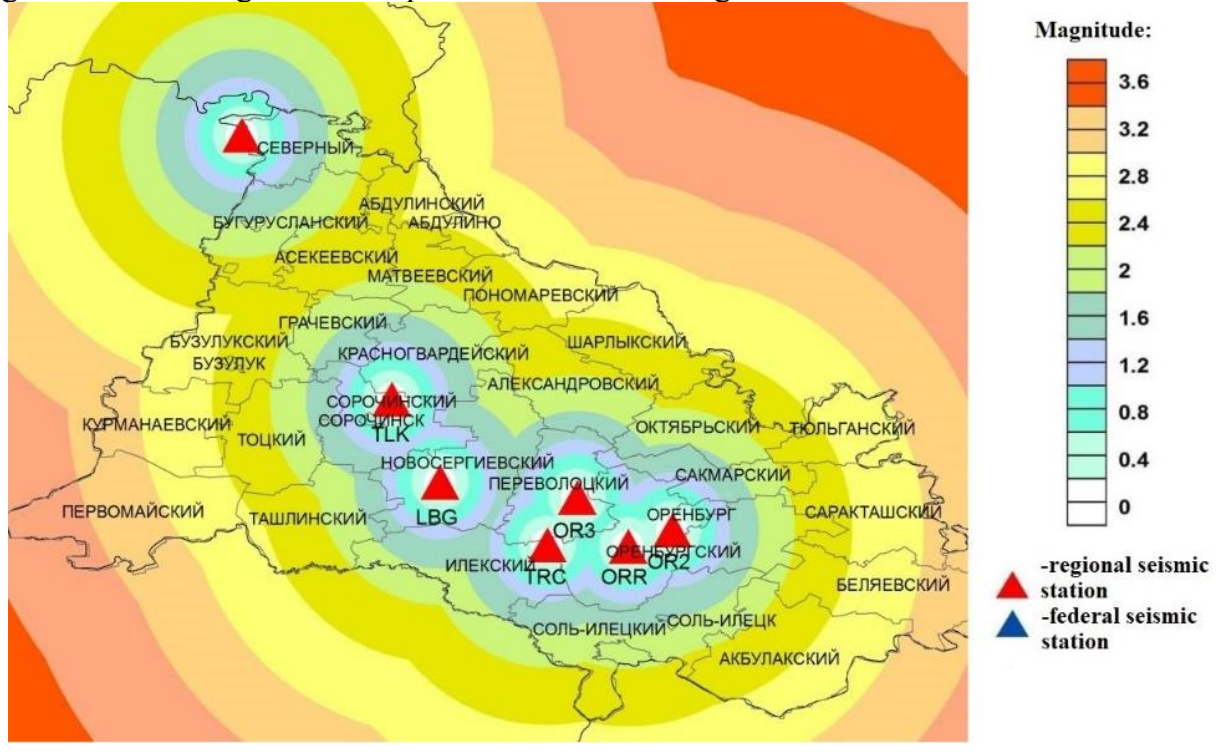

Fig. 1. Registration capabilities of a seismic stations network in the western Orenburg region.

At quarries and mines of Gaisky GOK earth's surface subsidence reaching $50 \mathrm{~cm}$ per year is registered [6]. The situation with connection of numerous seismic events with magnitudes $\mathrm{M}_{\mathrm{L}}$ 1.5-2.9 is of concern in Geoecology department of Orenburg Federal Research Center. These seismic events were recorded by stations of Orenburg Research Center and Kazakhstan national seismological network, located at a great distance from the area of Gaysky field. This does not allow to determine the source of seismic events, to determine their nature (rock impact, tectonic event, explosion, etc.), to identify stress zones in rock massifs, etc. 
Only in October 2019, Kazakhstan National Data Center has recorded more than 10 events that occurred in the eastern part of Orenburg region with magnitudes from 1.5 to 3.2. In fig. 2 events with a magnitude greater than two units that have occurred since beginning of the current year are noted.

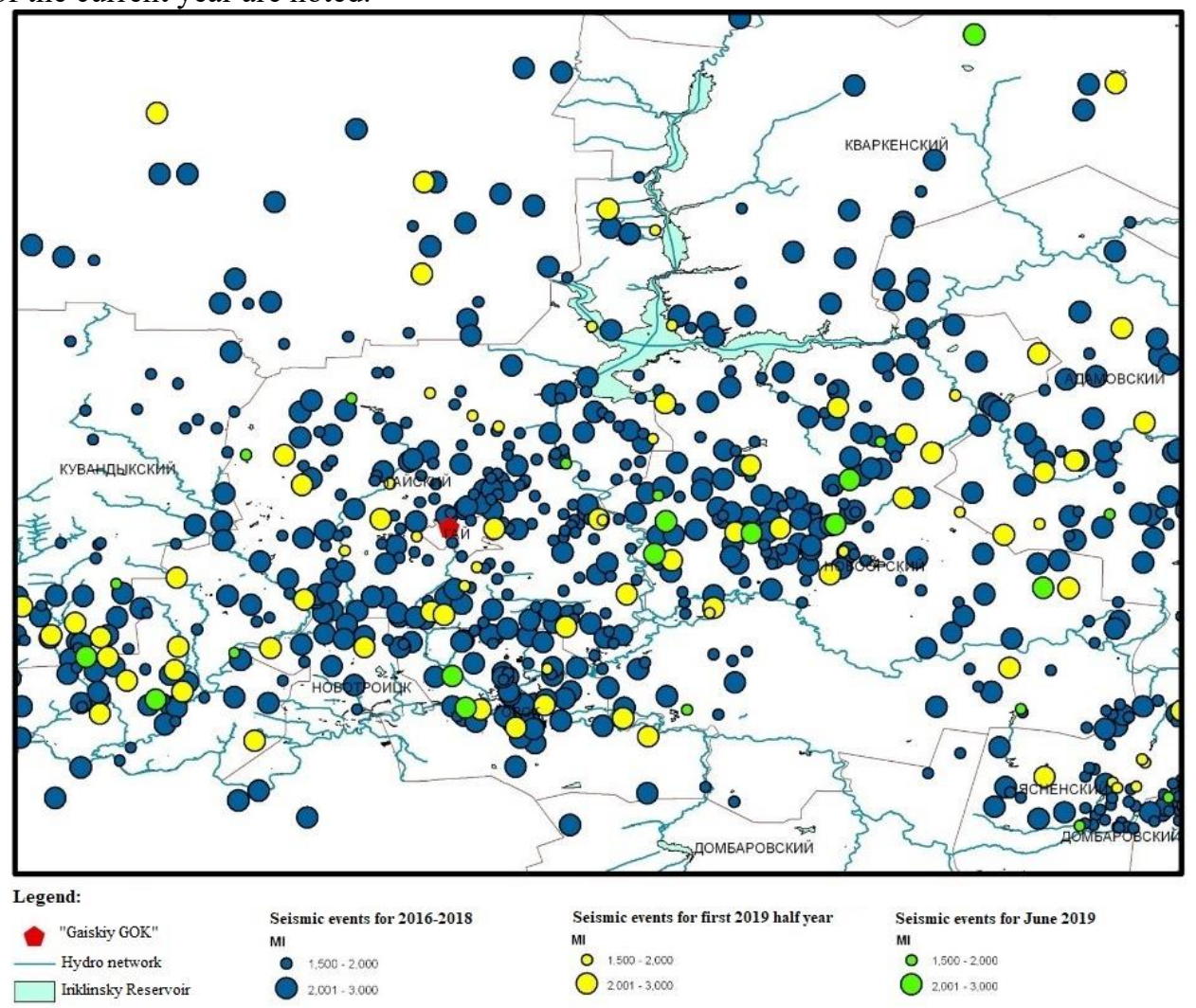

Fig. 2. Seismic events location on a map of the Orenburg region recorded by Kazakhstan National Data Center for January-October 2019

Using well-known methods for assessing a seismic regime for natural and man-made seismic events recorded in the eastern part of Orenburg region by seismic stations belonging to Kazakhstani colleagues, distribution of seismic events depending on a magnitude is compiled.

\section{Results}

Results of assessing the seismic regime in the eastern part of the Orenburg region are presented in Table 1.

Table 1. Seismic events distribution in the eastern part of Orenburg region depending on their magnitude.

\begin{tabular}{|l|c|c|c|c|c|}
\hline Magnitude range, $M b$ & $(0 ; 2]$ & $(2 ; 2.5]$ & $(2.5 ; 3]$ & $(3 ; 3.5]$ & $(3.5 ;+\infty)$ \\
\hline Number of seismic events, $N$ & 220 & 529 & 153 & 12 & 2 \\
\hline $\begin{array}{l}\text { Logarithm of seismic event } \\
\text { number, } \ln N\end{array}$ & 5.4 & 6.27 & 5.03 & 2.49 & 0.69 \\
\hline
\end{tabular}


According to data presented in the table, the plot of seismic events frequency for the period from 2016 to present is constructed (Fig. 3).

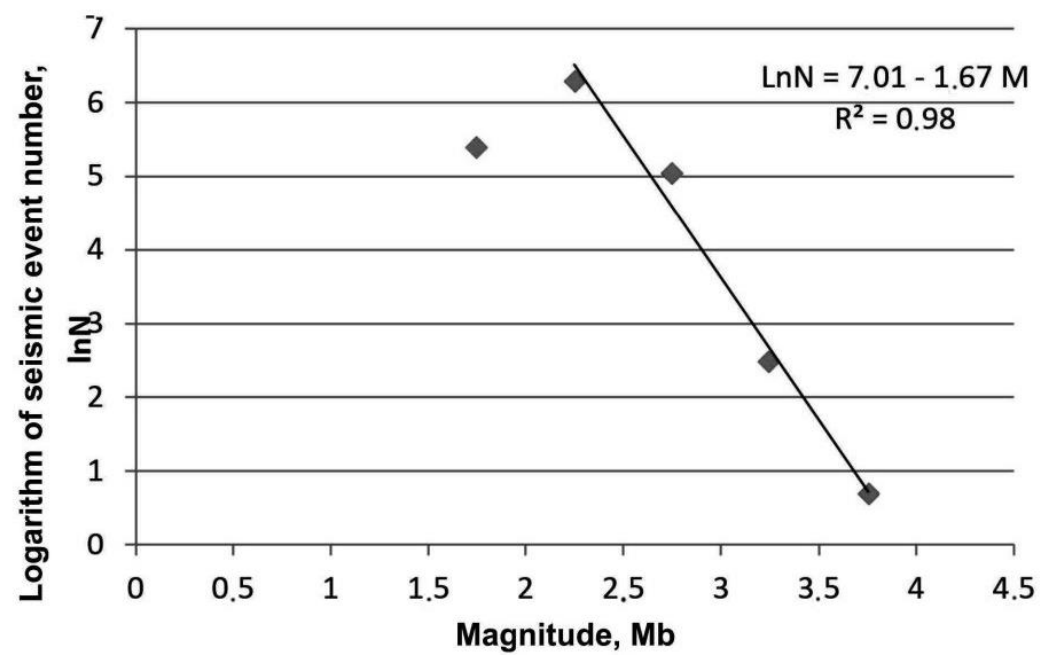

Fig. 3. Seismic events frequency for the period from 2016 to present

Selecting a linear section, we obtain the following dependence of number of seismic events logarithm on magnitude:

$$
\lg N=7.01-1.67 \cdot M
$$

The result obtained can be interpreted as follows. For natural and man-made earthquakes recorded in the territory under consideration, a deviation from the straight line is observed, reflecting a linear relationship between a magnitude and a number of events in the area of a weak seismic events with a magnitude of less than 2 .

The slope coefficient of a repeatability plot, which is one of the main indicators of a seismic regime, has an absolute value of $b=1.67$, significantly exceeding natural seismicity with the value of $b=0.75$, which is characteristic of technogenic and technogenic-induced seismicity. Therefore, the main source of increased seismic activity of a subsoil in the eastern Orenburg region is a technogenic load.

\section{Conclusions}

Seismological monitoring is required to study an abnormally high seismic activity in the East Orenburg region, identify its causes and sources, level of danger, develop measures to reduce seismicity and increase protection of specific objects of society, industry and energy. Seismic stations of Kazakhstan National Center are located at a distance of several hundred kilometers from large cities, industrial and energy facilities. It does not allow obtaining sufficient information on a seismic activity of the eastern Orenburg region. A seismological network created in Geoecology department of Orenburg Federal Research Center in the western Orenburg region cannot solve assigned tasks due to remoteness and geological conditions for seismic waves passage through Ural Mountains. To solve them, it is necessary to create a seismological network of 3-4 seismic stations in the territory of seismic activity in Gai and Novoorsk regions near Iriklinskaya State District Power Station and Iriklinsk Reservoir. 


\section{References}

1. S. Gibowicz, S. Lasocki, Adv. Geophys 44, 39-180 (2001)

2. J. Suckale, Adv Geophys 51, 55-106 (2009)

3. A. Tsviak, M. Nesterenk, A. Nesterenko, ISEES (2018) DOI:10.2991/isees-18.2018.100

4. M. Nesterenko, Yu. Nesterenko, OSU Bulletin 9, 122-127 (2010)

5. Yu. Nesterenko, M. Nesterenko, M. Karpyuk, Risk Analysis Issues 2, 48-54 (2010)

6. V. Gorbunov, Yu. Kantemirov, Geomatika 2, 70-76 (2013) 